\title{
GAMIFICATION IN TEACHING THEORETICAL LINGUISTIC DISCIPLINES
}

\author{
Leila Mirzoyeva \\ Suleyman Demirel University, Kazakhstan
}

\begin{abstract}
Gamification in the learning process is a well-known and, at the same time, an entirely new teaching tool. Today, a number of gaming techniques can be attributed not only in the real classroom, but also in the virtual learning environment. In both cases, games have significant motivating potential. On the other hand, prospects for the modern world development require getting both theoretical knowledge and practical skills, and games provide all the opportunities for getting them.

Traditional team games, as well as contests between individuals, are widely used in learning process at universities Moreover, there are various types of up-to-date platforms for creating and introducing online games such as Kahoot!, Quizlet, Plickers, Classcraft, etc. However, it should be noted that all the listed platforms and techniques are used primarily in teaching practical disciplines (e.g. Practical English) while for theoretical courses, traditional teaching methods and teacher-centered approaches continue to prevail. We believe that various techniques of gamification (both real and virtual) will increase the level of students' motivation while studying theoretical courses. Thus, such disciplines as Research Techniques in Linguistics, is a very complicated course for the $3^{\text {rd }}$ year BA students; so in order to motivate them, different games were introduced. In our research, we used a questionnaire aimed at finding out how the introduction of games enhances students' motivation to study this discipline.

Also, the experiment which lasted for 1 semester with the students whose major is "Foreign Philology", showed that the application of different games a) motivated students and activated their schemata; b) facilitate mastering complicated theoretical concepts; so gamification should be considered as an effective tool in teaching theoretical disciplines.
\end{abstract}

Keywords: Gamification, online platforms, Quizlet, Research Techniques in Linguistics, team games.

\section{Introduction}

The application of games in the learning process has a very long history. It may be considered as both a traditional and innovative teaching technique, especially nowadays, when a number of gaming technologies can be attributed not only to the interaction between students in a real classroom (in this case, various types of team and individual games can be used), but also to a plethora of games on cyber-platforms also having significant motivating potential. 
Traditional team games and contests that take into account students' individual achievements are widely used in the educational process nowadays. Moreover, there are various types of up-to-date platforms, such as Kahoot!, Quizlet, Plickers, Classcraft, etc. whose importance have been realized by most of the teachers under the pandemic condition. However, it should be noted that all the listed games are used primarily in the process of teaching practical disciplines, while in the case of theoretical courses, traditional methods of teaching continue to prevail. The author of the given research believes that various types of gamification (i.e. person-to-person interaction, cyber games etc.) will motivate students to study theoretical courses as well. For instance, gamification is considered as an effective tool in teaching such theoretical courses as Research Techniques in Linguistics.

\section{Literature Review}

The term gamification was invented by the digital media industry, but it means "using game design elements in non-game context" (Deterding et al. 2011, 9). Gamification is the application of game elements in non-gaming situations, that is, to convert useful activities into games (Deterding et al., 2001).

Thus, F. F.-H. Nah et al. (2014) identified eight game design elements that are used extensively in the educational and learning contexts. Those elements are: the point system which "functions as a measure of success or achievement", and it is also stated here that "points can also be considered as credits in an academic environment"; levels/stages system "used in various game designs to give players a sense of progression in the game"; badges "recognized as a mark of appreciation or task accomplishment during the process of goal achievement" and used to maintain learners' motivation; leaderboards keeping the learners motivated; prizes and rewards; progress bars; storyline which "refers to the narrative or story in the game", and a feedback which should be frequent, intensive, and immediate to engage learners.

The purpose of most of the games is to combine extrinsic and intrinsic motivation to increase the involvement of participants - like techniques such as scoreboards and personalized feedback. As Kapp (2012) states, gamification can be used to promote learning because many of the elements of gamification are based on educational psychology and are techniques that designers of instruction, teachers, and professors have been using for years. Items such as assigning points to activities, presenting corrective feedback, and encouraging collaboration on projects have been staples of many educational practitioners. In other words, gamification is presenting non game-like tasks as more game-like. Another beneficial feature of gamification is that games are not tied to the physical classroom and usually they can be played whenever the teacher and the student 
wants. However, this approach is controversial as some specialists support the idea of teachers giving instructions and controlling the game process, while others encourage the idea of allowing students to play games during their free time. Anyways, teachers' roles can not be excluded, because instructions which teachers give before the game are very important. Thus, games are supposed to be played during lessons with teachers being present before, during and after the gamified learning process. Harviainen et al. (2013) underline the fact that gamified learning should not lead to learning in a way that teachers become an external observers and they highlight that teachers' contribution is crucial when a gamified learning experience is planned and divided into stages. Saying simply, the use of games should be pedagogically meaningful and planning it appropriately requires a lot of time. Fui-Hoon (2014) also stated the meaningful integration of games into teaching and emphasizes careful planning and goal setting especially with informal games, games that were not designed for educational purposes.

The importance of gamification is becoming more and more obvious in the Kazakhstani context as well. Thus, Ostrovskaya (2017) highlighted that by means of gamification "the development of Kazakh students will take place through the introduction of active forms of education, which provide students with the opportunity to develop their functional literacy in independent way, with a great desire to develop communication skills together with their peers, and be creative in solving problems" (Ostrovskaya, 2017). The concept of gamification is to teach language through games thus making the learning process more engaging and comprehensible. Unfortunately, not all schools and universities in our country are equipped enough to implement gamified learning in the teaching process. That is why most teachers tend to stick to traditional teaching methods such as: drilling, using objects or just giving handouts. Sometimes, even in equipped classes, teachers continue to ignore digital tools because of lack of experience or knowledge in using computers, mobile phones and the Internet. Otherwise, gamification ultimately promotes learning by allowing students to monitor their own progress; students can control their own learning and repeat tasks wherever and whenever they want, and students can choose the amount of time they can spend reviewing materials. Some students can be encouraged by class recognition on the award board. Competition and rewards help to involve learners' attention to technology-related games.

\section{Research Design}

As the purpose of this research paper is to identify whether gamification is effective or not in teaching theoretical subjects such as Research Techniques in Linguistics, so a mixed design method seemed to be the most appropriate. To 
reach the aforementioned aims we conducted surveys at the end of the experiment and made observations of students' behavior while conducting the experiment. One of the most important problems is that the researchers should examine the results from different perspectives by adding not only students' opinion concerning motivational potential, but also their ideas about the effectiveness of games in a theoretical discipline study. Initial qualitative data were inspected through the questionnaire (see the Diagrams below).

\section{Research Questions}

The researcher will try to answer the following research questions:

1. Is gamification more effective than traditional teaching methods?

The result is going to be reached by implementing gamification in one group - experimental, and maintaining the existing method in the other group the control one. By the end of the experiment, the researchers will be able to find the differences, compare the results and identify whether gamification is a more effective method than other methods.

2. How can online platforms be implied in teaching theoretical disciplines?

\section{Research Population}

As it was stated before, the experiment was conducted with Foreign Philology students (43 third year students exactly, at the age between 20 and 23). There were 2 groups, experimental (22 students) and controlling (21 student),

\section{Research Results}

Educational games can facilitate the learning experience and the use of games in the classroom is very beneficial for students (Kiryakova, Angelova, Yordanova, 2014). Students may give up because of the failure, but due to the concept of games, students can react differently. In other words, games encourage students to learn better and succeed in the game process. Vesa (2017) mentioned in their study that educational games are able to meet at least three types of learners' intellectual needs (namely, cognitive, emotional and social needs), thus creating a positive emotional experience. Cognitive advantages include the development of problem - solving and critical thinking skills. In order to win and pass to the next level, students have to complete tasks successfully. The rewards provided at the end of each game lead to increased motivation. Another beneficial effect of gamification is that students learn to control emotions. In order to win, learners cope with losing, improve language skills and obtain new learning techniques. Immediate feedback helps to identify mistakes and improve them thus 
increase motivation to win. However, if students fail in a traditional classroom, it is difficult to turn negative emotions into positive.

\section{Gamification in Teaching Research Techniques in Linguistics: Game-Contest}

In our opinion, if theoretical subject is studied in English, gamification can serve as a multifunctional tool that

- allows to increase students' motivation and shows that theoretical courses are not just a "baggage of knowledge", but also have undoubted practical applicability;

- provides opportunities for developing language skills in English for Specific Professional Purposes;

- $\quad$ is considered as a necessary part of the Classroom Management.

Also, in this case the predominance of student-centered approach is quite obvious, so it is beneficial for students.

Implementation of game-contest in teaching Research in Linguistics can be described as follows:

Stage 1. Managing sub-groups for game-contest.

Stage 2. Developing scenario for conducting game-contest. Undoubtedly, mainly seminar or self-study classes are conducted under the guidance of the teacher. At the same time, contest can be used while presenting new material, i.e. in lectures.

At the second stage of developing training material, the teacher should take into account such factors as:

- level of theoretical knowledge in the field of subject;

- level of language competencies;

- psychological atmosphere in each group/team;

- personal characteristics of students.

Typically, game-contests between randomly organized teams give teachers the opportunity to check how well the main concepts of Research Techniques are mastered and to provide an emotional background, to motivate students, to develop creative presentation of theoretical material.

Here are some questions suggested for the game-contest between several teams:

1. Which of the research techniques examines a small number of units across a large number of variables and conditions?

2. ... investigates patterns and sequences of growth and / or change as a function of time?

3. Name the step which is common for all the research methods 
4. Which method doesn't involve total experiment?

5. The developmental research consists in...

6. Four basic differences among the Corpus-based or Corpus-driven approaches are...

7. Name the essential feature of a Corpus-based approach...

8. Four basic steps for formulating research questions are...

These questions, which we propose for the first stage of the game, require both quick responses (as the speed is also assessed), and correct answer as well as creative approach (since the theoretical concepts should be mastered). Also, in order to provide the correct and complete answer, students should establish clear logical links between terms, definitions and peculiar features of every particular concept (e.g. corpus-based approach, developmental research etc.) Within the first stage, time for reflection is limited, the team that gives faster and more accurate answer gets more points.

The second stage of the game is aimed at eliciting more detailed responses, which requires a developed language competence in both oral and written speech (it is required from the team members to give a written outline of the answer in advance), and full mastery of concepts from the sphere of the theory of literature, e.g.:

Provide your own examples of: historical research/descriptive research/ any main-research question/causal-comparative research.

Similar stages of the game were suggested in the course of the experiment and in the analysis of concepts related to practical application of various research techniques:

1. Provide your own examples which illustrate the opposition between Intuition and Corpus...

2. List the rules related to the choice of research design. How can you apply them in your own research?

3. Name the data collection strategies. Which of them will be the most appropriate for your research?

4. How will you provide the credibility while collecting data?

Apart from that, there are some practical tasks in the contest: Analyze the following extract from Historical research / Descriptive research viewpoint; what kind of questions will you formulate in order to write an article?

\section{Gamification via Online Platform}

As it was highlighted by methodologists, a variety may be considered as a sign of good teaching. So, while choosing this or that technique, the teacher defines the objectives of a certain lesson. In our case, the use of such programs as Kahoot!, Plickers and Quizlet in teaching Research Techniques facilitates 
students' perception. After all, as we said above, traditional methods of teaching is not always effective. Otherwise, university instructors do not often use the programs mentioned above, as it is not always possible to cover all the research problems and aspects with one program. Moreover, those programs require careful preparation of both teachers and students. Thus, the most important thing in using Quizlet is to elaborate the appropriate content for the Quizlet cards to activate students' schemata. In this case, instead of learning theoretical concepts by heart, students will grasp all the details.

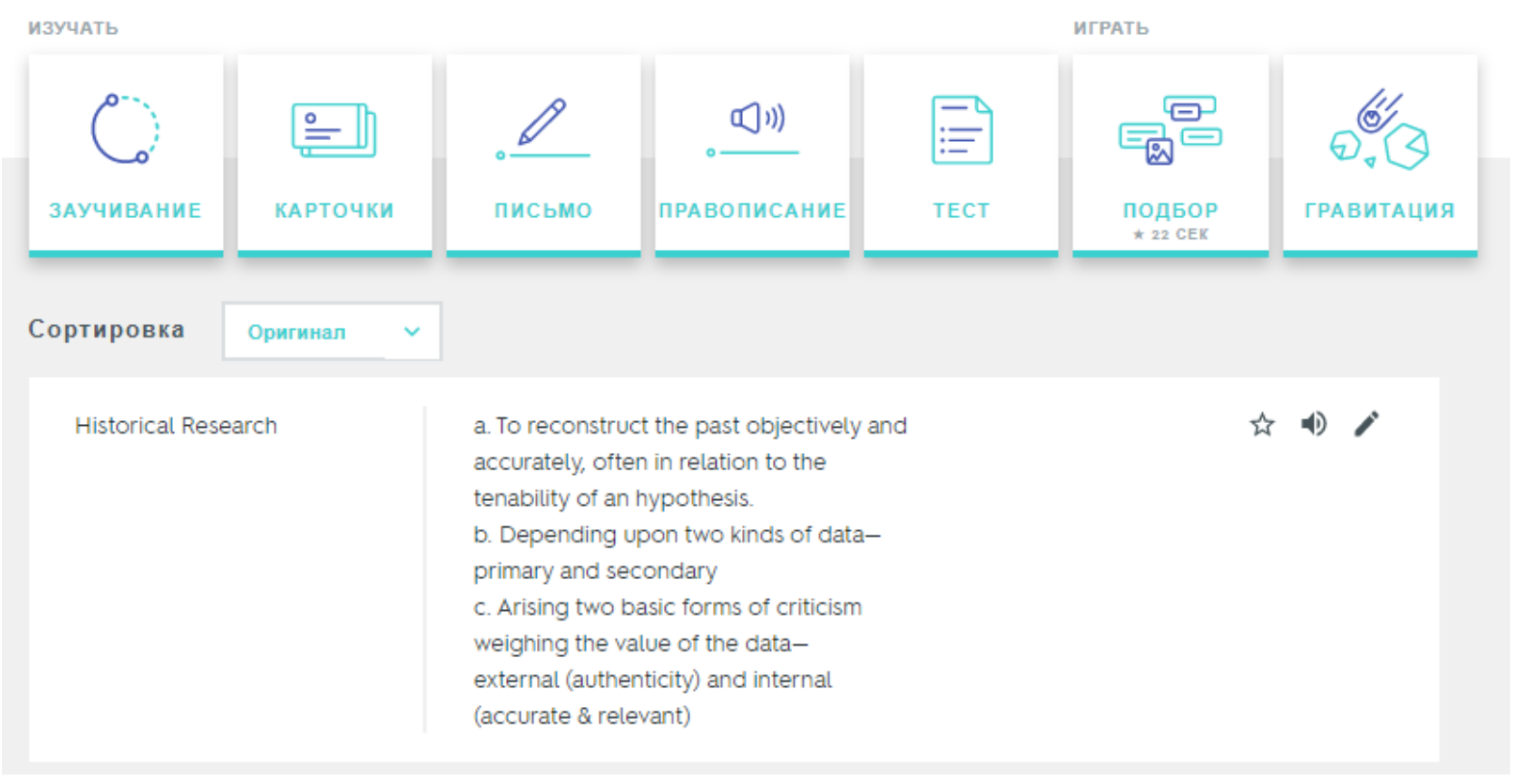

Figure 1 Quizlet Cards for Research Techniques in Linguistics

Instead of drilling exercises and memorization, doing a variety of tasks, e.g. matching exercises in the form of game, seems to be much more beneficial for students as it will be shown below. Also, there are specific tools for counting students' results, control and statistics, which helps to track students' progress. That is why those games can be used not only in the classroom, but also for extracurricular work. The functions of gamification are also diverse: wide opportunities of the Quizlet, Kahoot and similar programs allow students to understand and conceptualize main ideas of the course. 


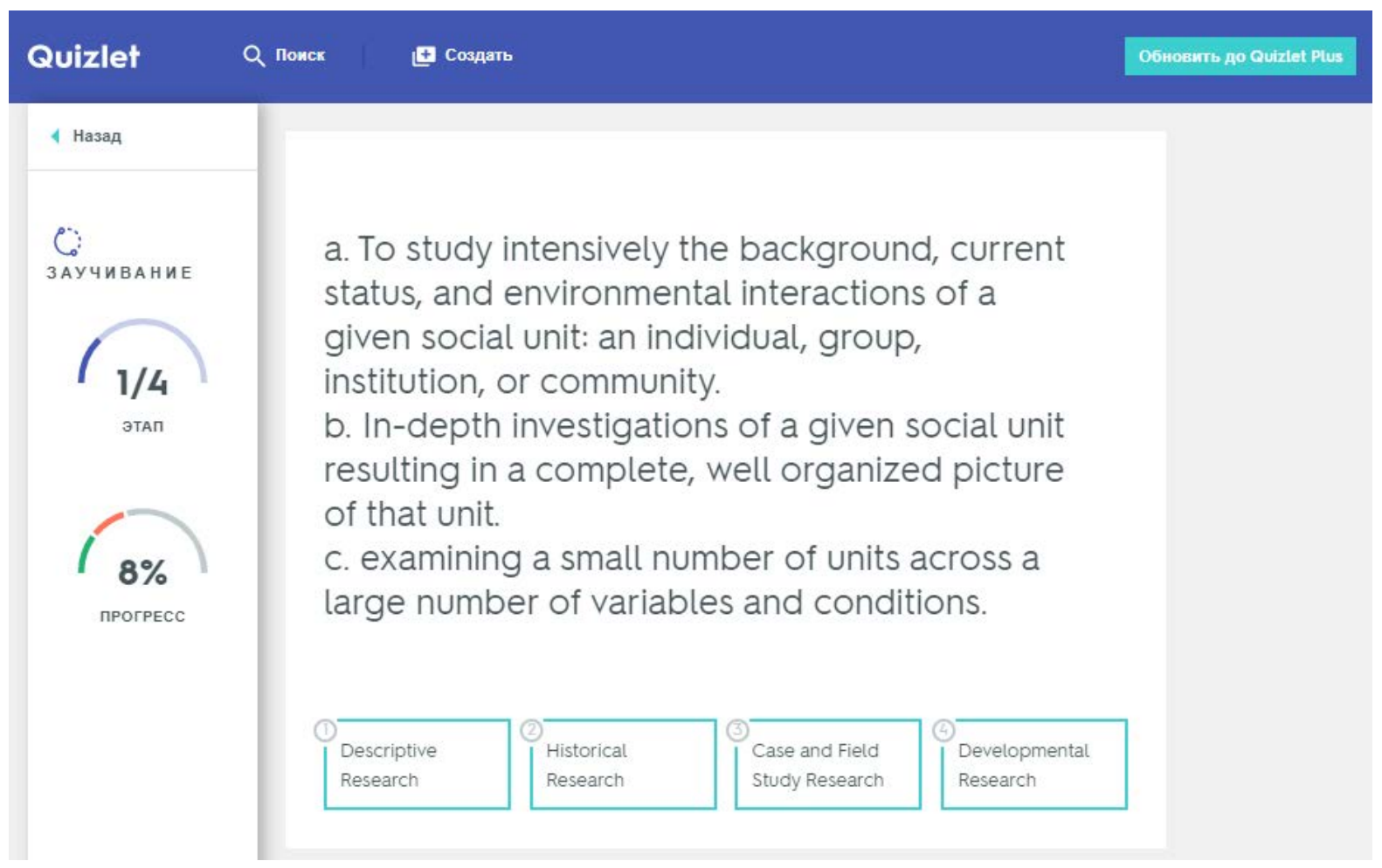

Figure 2 Applying Quizlet for Conceptualization

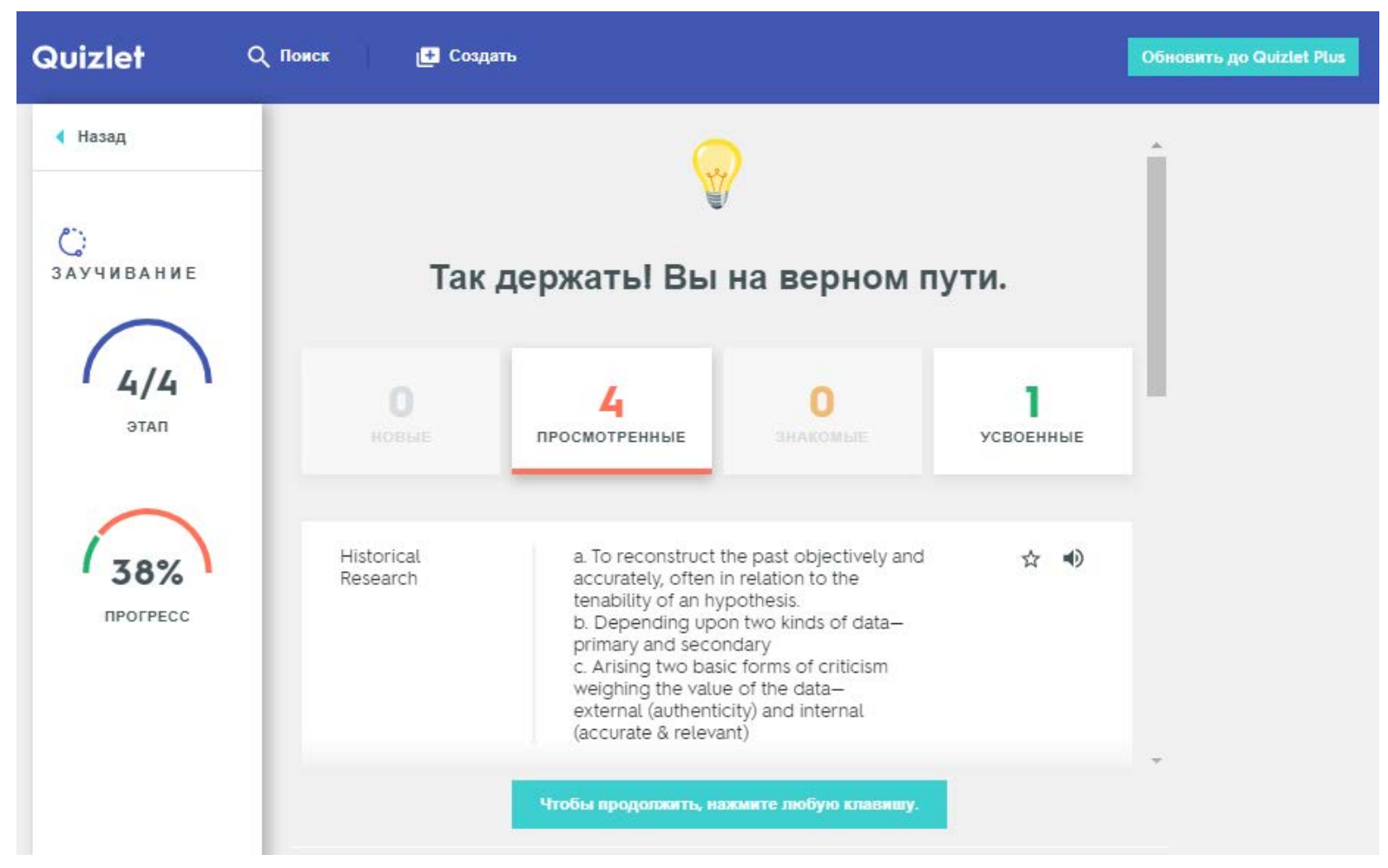

Figure 3 Shows Motivating Character of Program's Response 
In the case of mistakes, the program automatically shows the correct option/answer; therefore, students get the opportunity not only for self-control, but also for mastering material that has not been understood yet and learned sufficiently. The fact that the material is represented in the form of a computer game also motivates students, since modern learning is impossible without the use of computer technology.

\section{Gamification in the Teaching of Theoretical Discipline through the Eyes of Students}

Based on the results of our experiment (it was conducted during one semester for the specialty "Foreign Philology"), a survey was conducted. The questionnaire was aimed at finding out how the introduction of gaming technology enhances the motivation of students in the study of theoretical discipline (Research Techniques in Linguistics). The results of the questionnaire are presented on the following diagrams:

Figure 4 shows the use of gaming technology helped me in mastering complex theoretical concepts.

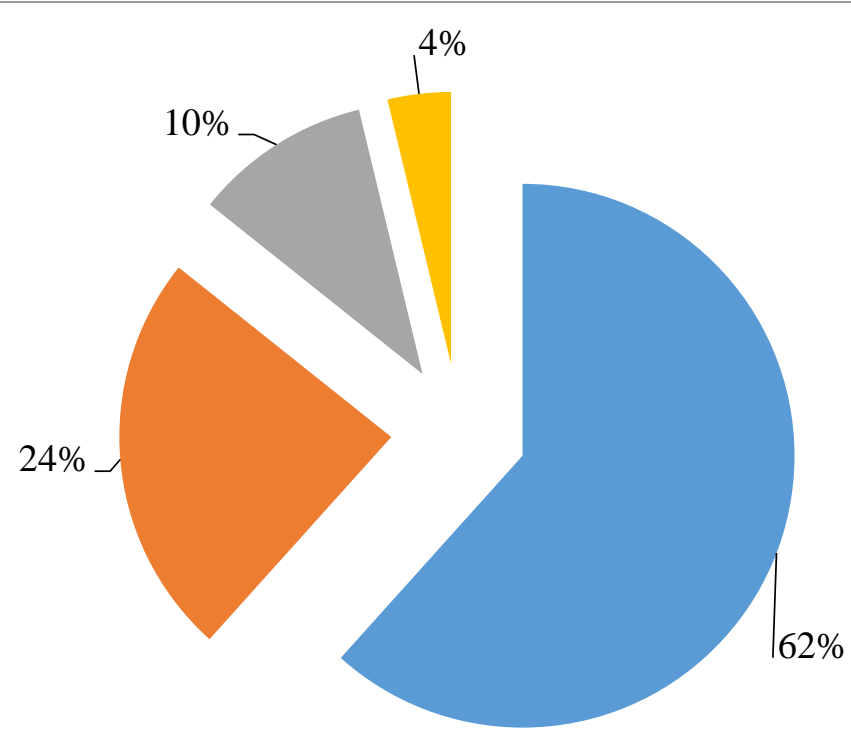

- Completely agree, high efficiency - $62 \%$

घgree, quite high efficiency $24 \%$

- Partially disagree, average efficiency - $10 \%$

Strongly disagree, low efficiency - $4 \%$

Figure 4 Mastering Theoretical Concepts

Figure 5 show the use of gaming technology has made the subject emotionally attractive. 


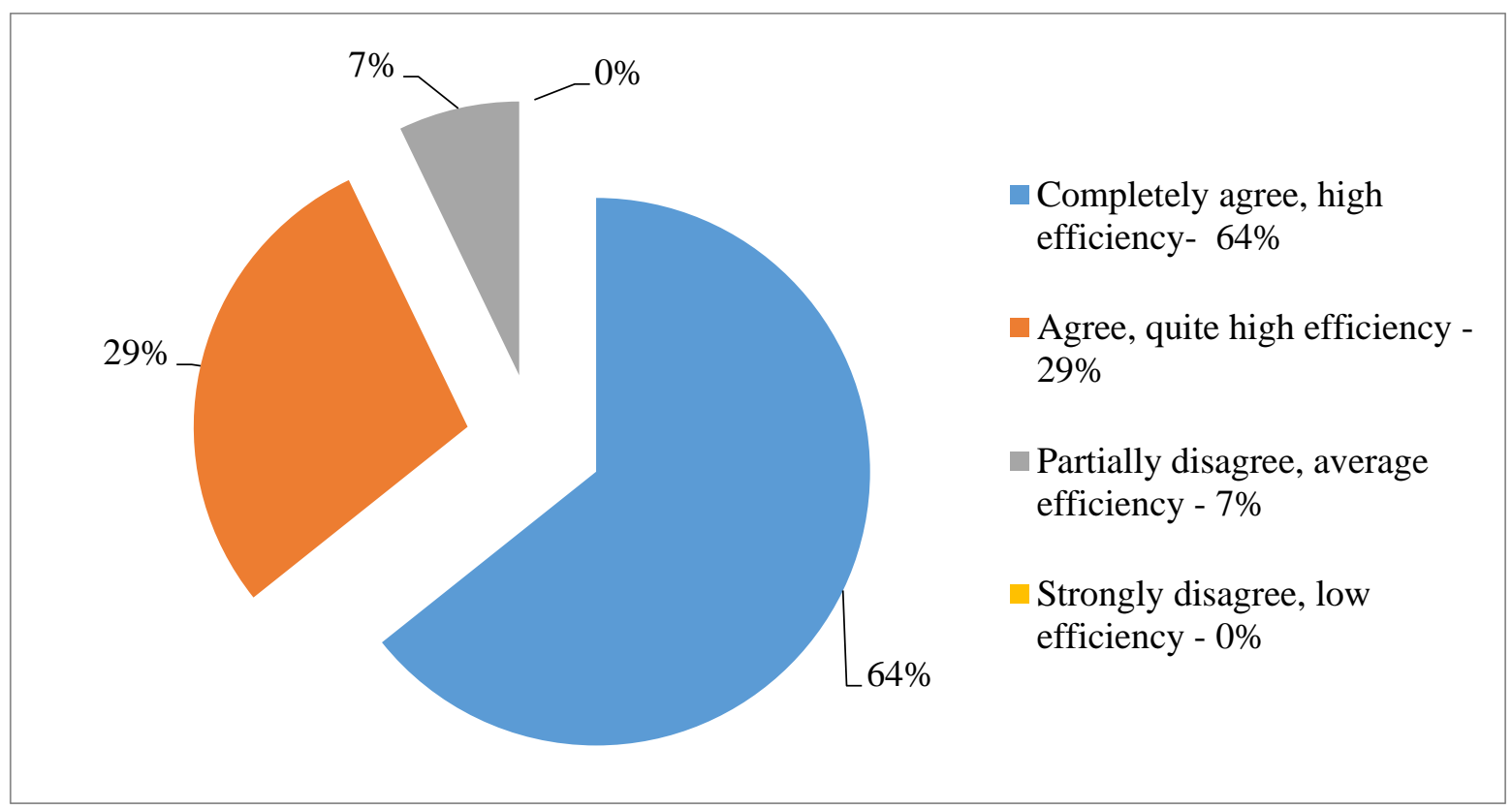

Figure 5 Emotional Attractiveness

Figure 6 shows the use of gamification allows you to develop analytical skills

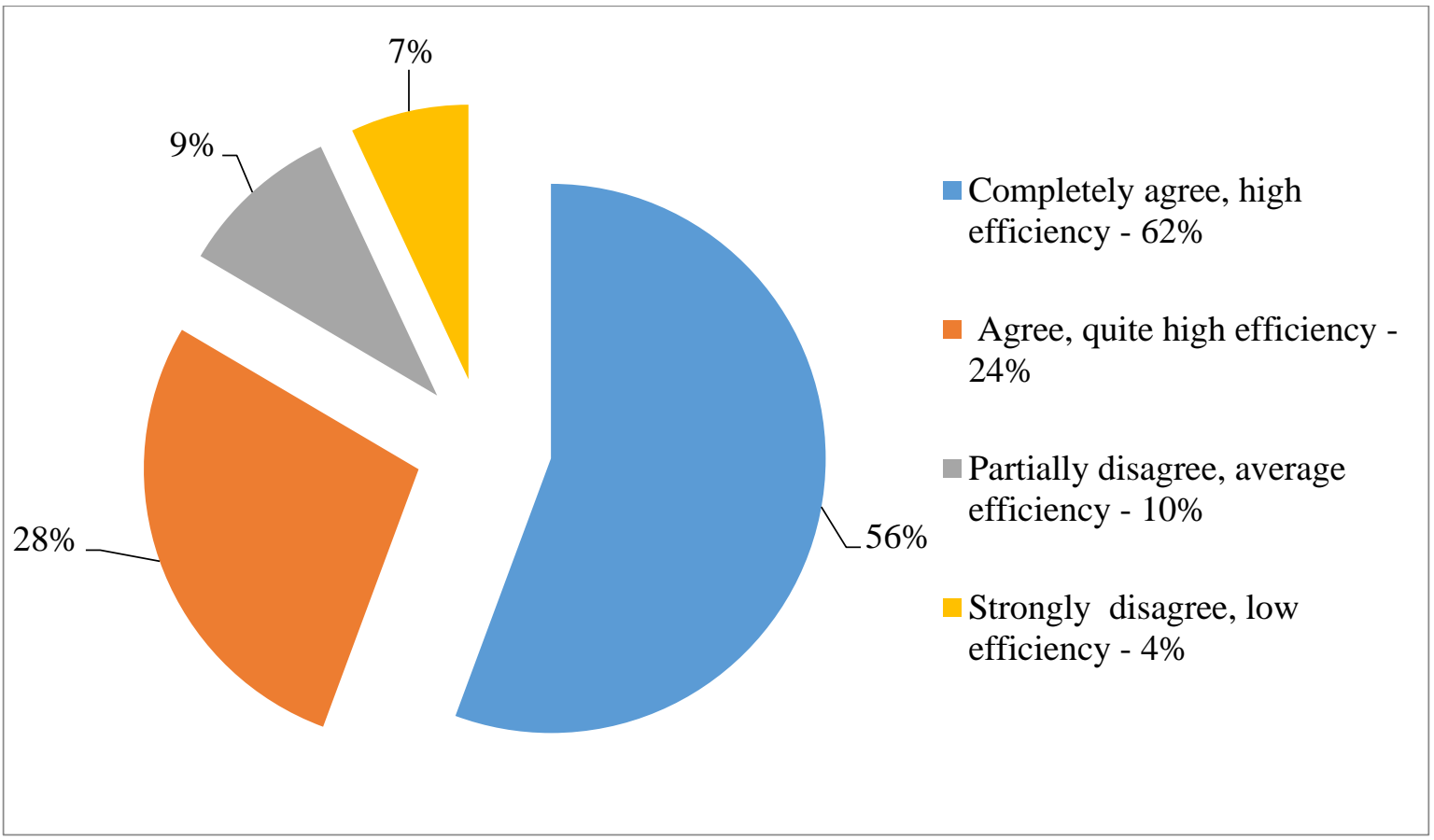

Figure 6 Development of Research Analysis Skills

The results of the survey showed that the students appreciated not only the emotional attractiveness of the use of gamification, but also the opportunities that are provided for mastering theoretical concepts in the process of using them. Thus, 
$64 \%$ fully agree with the fact that the introduction of games into the structure of the class significantly enhances its emotional attractiveness; $29 \%$ believe that the efficiency is high enough; The negative answer is not chosen by students at all. The possibility of mastering complex theoretical concepts was evaluated somewhat differently, since a small part of the students expressed disagreement (4\%). At the same time, the percentage of those who positively evaluated this possibility is also significant (62\% of the respondents rated it highly, 29\% rated efficiency as high enough). Similar results were obtained in reference to the development of research analysis skills (7\% of the respondents expressed their disagreement with the statement about the possibility of developing these skills through the gamification, while 56\% expressed high efficiency in the use of gaming technologies in this aspect). In general, the students appreciated the possibilities of gamification used in the teaching of theoretical disciplines, noting also the creation of a positive emotional atmosphere and a motivating effect. Moreover, Figure 7 shows differences between the midternd exam results of experimental and controlling groups.

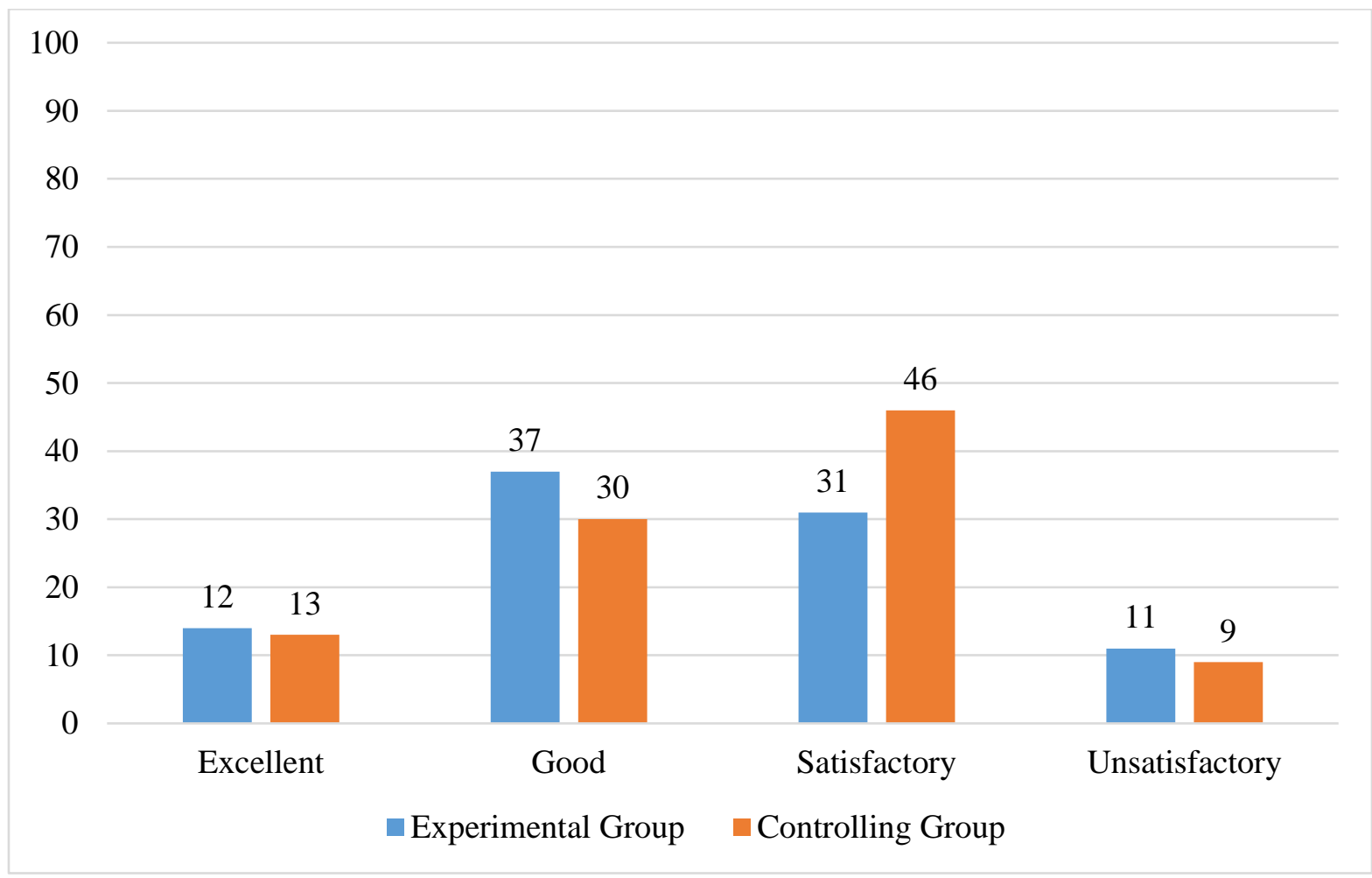

Figure 7 Midterm Test Results in Experimental and Controlling Group, \% 


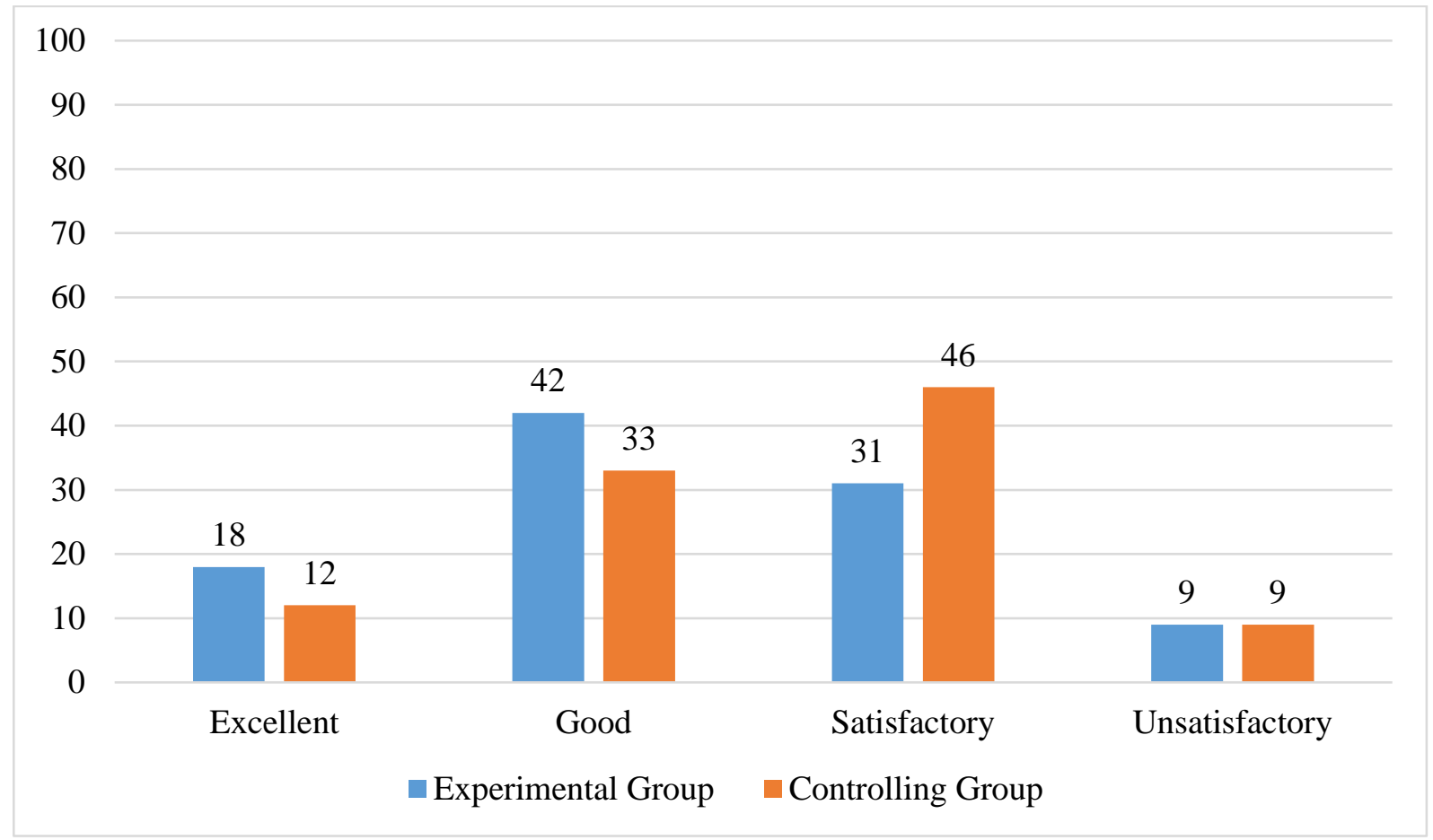

Figure 8 Final Exam Results in Experimental and Controlling Group, \%

Thus, the differences between two diagrams represent the progress in both groups; on the other hand, Figure 7 shows that results of the midterm test were to some extent better in controlling group than in the experimental one, whereas final results (Figure 8) demonstrate a considerable progress of experimental group. In our opinion, the general trend represented on the diagrams indicate the efficiency of gamification in teaching theoretical discipline.

\section{Conclusion}

Although the definition of gamification in educational context is not a new phenomenon, the use of both interpersonal interaction and digital games to support the learning process is a recent development, many scientific works were held on that topic.

Thus, gamification in the study of the research techniques also has significant motivating capabilities; they are adapted to the perception of a modern student and allow replacing the mechanical repetition and memorizing with an engaging game where the interactive "partner" is a game training program. 
In general, in contemporary higher education system, while teaching theoretical subject (e.g. Research Techniques in Linguistics) games are used in the following cases:

- As independent technologies for mastering the concept, topic and even the division of the subject;

- $\quad$ As an element of a more general technology;

- As a lesson or part of it (introduction, control);

- $\quad$ As an element of out-of-class work to popularize the course.

So, an element of competition is introduced into study, therefore the didactic task has been completely transformed.

\section{References}

Deterding, S. (2012). Gamification: designing for motivation. Journal Interactions, Volume 19, Issue 4, 14-17.

Kapp, K.M. (2012). The gamification of learning and instruction: Game-based methods and strategies for training and education. San Francisco, CA: Pfeiffer.

Fui-Hoon Nah, F., Qing, Z. (2014). Venkata Rajasekhar Telaprolu, Abhishek Padmanabhuni Ayyappa, and Eschenbrenner, B. Gamification of Education: A Review of Literature, F.F.-H. Nah (Ed.): HCIB/HCII 2014, LNCS 8527, 401-409, 2014. Springer International Publishing, Switzerland. Retrieved from: file:/Users/Lenovo/Documents/Nah2014_ Chapter_GamificationOfEducationAReview.pdf

Kiryakova, G., Angelova, N., Yordanova, L. (2014) Gamification in Education: 9th International Balkan Education and Science Conference. Edirne, Turkey. Retrieved from http://www.sun.ac.za/english/learning-teaching/ctl/Documents/Gamification\%20in\% 20education.pdf

Ostrovskaja, N.I. (2017). Obnovlenie soderzhanija obrazovanija v Respublike Kazahstan. Retrieved from: URL https://nsportal.ru/blog/nachalnaya-shkola/all/2017/03/23/ obnovlenie-soderzhaniya-obrazovaniya-v-respublike-kazahstan

Vesa, M., Hamari,J., Harviainen, J.T., Warmelink, H. (2017). Computer games and organization studies. In: Organization Studies, 2017, 223-261. 